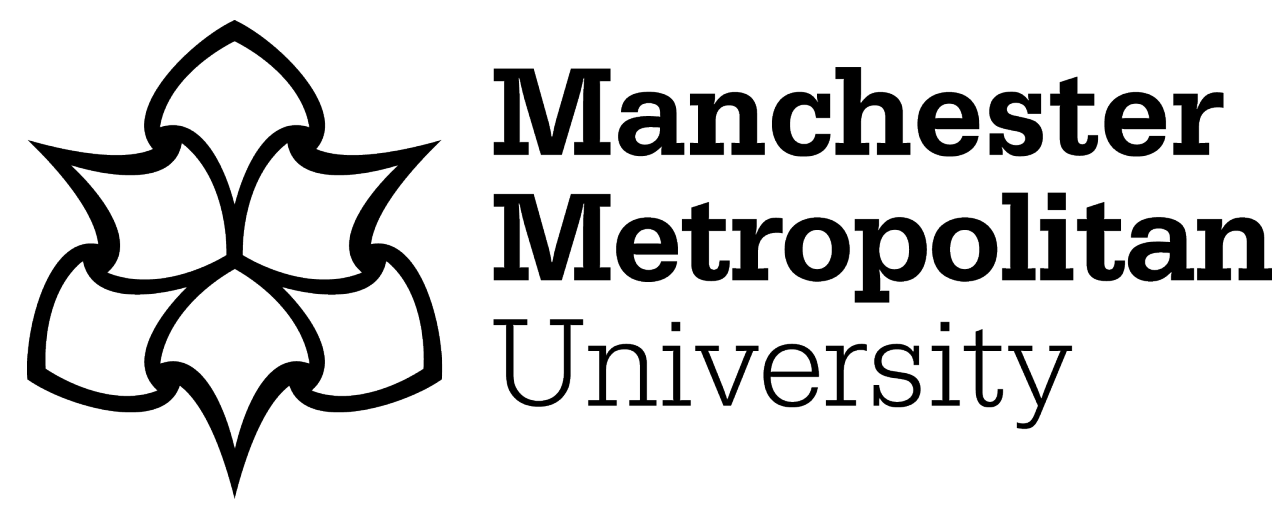

Goodley, D, Runswick-Cole, K ORCID logoORCID: https://orcid.org/00000001-9658-9718 and Liddiard, K (2016) The DisHuman Child. Discourse: studies in the cultural politics of education, 37 (5). pp. 770-784. ISSN 01596306

Downloaded from: https://e-space.mmu.ac.uk/596723/

Version: Published Version

Publisher: Taylor \& Francis

DOI: https://doi.org/10.1080/01596306.2015.1075731

Usage rights: Creative Commons: Attribution-Noncommercial-No Derivative Works 4.0

Please cite the published version 


\section{Discourse: Studies in the Cultural Politics of Education}

\section{The DisHuman child}

\section{Dan Goodley, Katherine Runswick-Cole \& Kirsty Liddiard}

To cite this article: Dan Goodley, Katherine Runswick-Cole \& Kirsty Liddiard (2015):

The DisHuman child, Discourse: Studies in the Cultural Politics of Education, DOI:

10.1080/01596306.2015.1075731

To link to this article: http://dx.doi.org/10.1080/01596306.2015.1075731

\section{(c) 2015 The Author(s). Published by Taylor \& Francis.}

Published online: 06 Oct 2015.

\section{Submit your article to this journal ש}

Џ Article views: 672

Q View related articles $\sqsubset$

View Crossmark data $\nearrow$ 


\title{
The DisHuman child
}

\author{
Dan Goodley ${ }^{\mathrm{a}}$, Katherine Runswick-Cole ${ }^{\mathrm{b}}$ and Kirsty Liddiard ${ }^{\mathrm{a}}$ \\ ${ }^{a}$ School of Education, The University of Sheffield, Sheffield, UK; ${ }^{b}$ Department of Psychology, Manchester \\ Metropolitan University, Manchester, UK
}

\begin{abstract}
In this paper, we consider the relationship between the human and disability; with specific focus on the lives of disabled children and young people. We begin with an analysis of the close relationship between 'the disabled' and 'the freak'. We demonstrate that the historical markings of disability as object of curiosity and register of fear serve to render disabled children as non-human and monstrous. We then consider how the human has been constituted, particularly in the periods of modernity and the rise of capitalism, reliant upon the naming of disability as antithetical to all that counts as human. In order to find a place for disabled children in a social and cultural context that has historically denied their humanity and cast them as monstrous others, we develop the theoretical notion of the DisHuman: a bifurcated complex that allows us recognise their humanity whilst also celebrating the ways in which disabled children reframe what it means to be human. We suggest that the lives of disabled children and young people demand us to think in ways that affirm the inherent humanness in their lives but also allow us to consider their disruptive potential: this is our DisHuman child. We draw on our research projects to explore three sites where the DisHuman child emerges in moments where sameness and difference, monstrosity/disability and humanity are invoked simultaneously. We explore three locations (i) DisDevelopment; (ii) DisFamily and (iii) DisSexuality illuminating the ways in which the DisHuman child seeks nuanced, politicized and complicating forms of humanity.
\end{abstract}

\section{KEYWORDS}

Children; disability; dishuman; human; disruption; monstrosity

\section{Introduction}

We begin our analysis of the affirmative possibilities given by attending to the lives of disabled children by recognising the lack of such generosity on the part of dominant culture and society. While we fundamentally believe that disabled children are key agents of change in rethinking how we might live our lives, enact educational policy and practice, work relationally and rethink key human concepts such as development, family and sexuality, it is important to acknowledge the huge body of critical disability studies literature that has documented the abuses, neglect and marginalization experienced by disabled young people (Curran \& Runswick-Cole, 2014; Haraldsdóttir, 2013; Skitteral, 2013). We 
write this at a time when our friend and colleague Dr Sara Ryan and her family are living with the heart-breaking experience of their son Connor Sparrowhawk - or Laughing Boy to his family (LB) - who died in a National Health Service (NHS) assessment and treatment unit in 2013. The JusticeforLB campaign ${ }^{1}$ has articulated the neglect and malpractice that led to this young disabled man being left unattended to drown in the bath at the unit. Sadly, LB's death adds to a long list of previous and contemporaneous cases of disabled young people whose lives appear not to have been valued in the same ways afforded to non-disabled children. ${ }^{2}$ How are disabled children and young people understood in our society in ways that permit such neglect to occur time and time again? One answer lies in the situating of disability as Other to mainstream understandings of the values we attach to human beings.

\subsection{A monstrous child}

This story shall go by itself; for I will leave it to physicians to discourse of. Two days ago I saw a child that two men and a nurse, who said they were the father, the uncle, and the aunt of it, carried about to get money by showing it, by reason it was so strange a creature. It was, as to all the rest, of a common form, and could stand upon its feet; could go and gabble much like other children of the same age; it had never as yet taken any other nourishment but from the nurse's breasts, and what, in my presence, they tried to put into the mouth of it, it only chewed a little and spat it out again without swallowing; the cry of it seemed indeed a little odd and particular, and it was just fourteen months old ....

Under the breast it was joined to another child, but without a head, and which had the spine of the back without motion, the rest entire; for though it had one arm shorter than the other, it had been broken by accident at their birth; they were joined breast to breast, and as if a lesser child sought to throw its arms about the neck of one something bigger. (De Montaigne, 1580)

Michele de Montaigne's essay Of a monstrous child (1580) is an example of what has become a well-worn cultural trope in the global North: the disabled child is a monstrous child. The killing of 'monstrous' babies born with 'deformities' has been traced back as far as the time of Aristotle (Rieser, 2006). In more recent times, monstrosity was the justification for the 'euthanasia programmes' that systematically killed hundreds of thousands of disabled children, and adults, from 1939 to 1945 in Nazi Germany (Evans, 2004). While we might hope to comfort ourselves by imagining that the image of the monstrous/disabled child is now no more than a historical relic, a contemporary Google search for 'disabled child' and 'monster' reveals, within the first two pages, the story of a father who describes being in a restaurant with his disabled son who is branded a 'monster' by another diner (Lee, 2010) and an anonymous mother's blog entitled The monster inside my son in which the mother describes her disabled child as a violent monster (Anon, 2009). Add to this well-worn narrative of disabled person as freak - and disabled object at the heart of the freak shows of Victorian England and contemporary reality TV programmes that equally objectify 'the disabled' as subject of cultural curiosity - and it would seem that disabled children continue to exist as dustbins of disavowal (Hevey, 1992).

The image of disabled child as monstrous has, of course, been contested. Indeed, De Montaigne, himself, attempts to rehabilitate the monstrous child by claiming:

Those that we call monsters are not so to God, who sees in the immensity of His work the infinite forms that He has comprehended therein; and it is to be believed that this figure which astonishes us has relation to some other figure of the same kind unknown to man. (De Montaigne, 1580, np) 
By adhering to the Judeo-Christian belief that we are all made in God's image (Genesis, 1, 17), De Montaigne is able to position monstrosity alongside humanity - this seemingly contradictory position is one that we return to below.

\subsection{Monstrosity and humanity}

As De Montaigne demonstrates above, discussion of the monstrous is inevitably bound up with discussion the human. Monsters provoke fear, but also fascination, as their ghostly presence, same but not quite, threatens to re-position or even to dissolve the boundaries of 'normality' (Shildrick, 1996). Shildrick (1996) describes monsters as 'out of control, uncontained, unpredictable, leaky': in other words they are women (Shildrick, 1996, p. 2), children and disabled people. Not surprisingly, given the conflation of disability and monstrosity, disability, too, is often invoked in discussions of the human (Kittay \& Carlson, 2010). The words 'person' and 'human' are used interchangeably but being born human is not enough for an individual to achieve the status of person (Taylor, 2013). This matters, because being seen as 'human but not quite', means that the associated human entitlements and protections may also be denied (Taylor, 2013). Eva Feder Kittay (2011) describes the ways in which those with 'severe cognitive impairments' have often been consigned to the category of 'human nonpersons' excluded from discussions about social justice because they are deemed to lack (narrowly defined conceptions of) 'capacity' and 'autonomy'. We share Rosi Braidotti's (2013) disillusionment with these narrow versions of the 'human norm that stands for normality, normalcy and normativity' (p. 26). This leads her to describe herself as an 'anti-humanist' (p. 16). We, like Braidotti, are critical of narrow concepts of the human that overshadow the lives of disabled people. However, in the political context of the global North, where human rights-based discourse is often invoked to assert disabled people's entitlements and protections (e.g. HMSO, 2010; United Nations, 2007), we find ourselves not yet ready to abandon the category of the human in the lives of disabled children, young people and adults. Rather, we want to remain critical of the category of the human, at the same time as we claim the human. We think that disability has the radical potential to 'trouble the normative, rational, independent, autonomous, subject that is so often imagined when the human is evoked' (Goodley \& Runswick Cole, 2014, p. 3). Just as Montaigne invokes humanity alongside monstrosity, we want to acknowledge humanity alongside disability in the lives of disabled children. For some, the logic of our argument itself is, perhaps, also monstrous, as we seek simultaneously to contest and to claim the (normative) human in the lives of disabled people, including, of course, children and young people as well as consider what happens to the category of human when it has been touched by the human diversity, difference and potentiality of disability (Goodley \& Runswick Cole, 2014). We find ourselves disavowing the human (we desire it but also resist its narrow confines) whilst re-centering disability as the space through which to rethink what it means to be human (acknowledge disability as the frame through which to think again). We are drawn too to the ways in which many individuals who are placed on the periphery of the human category seek to be recognised just like anyone else. This desire for the normative stuff of everyday human life (education, employment, rights to be 'independent', part of a community, rights/access to sex, marriage, family) marks what it means to be considered human. Simultaneously, we note that this appeal to sameness inevitably becomes necessarily troubled 
by diversity of the human condition expressed, for example, by those living with and through disability. This leads us then to the DisHuman condition.

\section{Introducing the DisHuman}

Elsewhere we have set out as this position in our discussion of DisHuman studies (Goodley \& Runswick Cole, 2014; Liddiard and Goodley, in press). DisHuman studies respond to what we describe as a dis/human reality:

one which, we contend, simultaneously acknowledges the possibilities offered by disability to trouble, re-shape and re-fashion traditional conceptions of the human (to 'dis' typical understandings of personhood) while simultaneously asserting disabled people's humanity (to assert normative, often traditional, understandings of personhood). (Goodley \& Runswick Cole, 2014, p. 6)

In our thinking so far, we have come across a number of bi-furcated examples of the DisHuman paradox which we originally set up as a number of fused binaries (Figure 1).

Goodley and Runswick Cole $(2014$, p. 6) acknowledge that 'our thinking is still in the early stages of germination in relation to this list of dis/human concepts'. This paper allows us to start pulling apart, interrogating and testing out the conceptual clarity and utility of these ideas. We want to ask what disability does to typical, common sense normative human categories of adult, child, youth and family. How might disability affirm some of the ways in which these categories are lived out whilst, simultaneously, demanding new ways of living (dis/life)? When we think of the goals of capitalism, science, medicine and citizenship, what assumptions are these huge societal practices based upon, and in what ways does disability disrupt these assumptions (dis/capitalism, dis/science, dis/ medicine and dis/citizenship)? In this paper, we extend this analysis in two ways. Firstly, we seek to work with the seemingly contradictory though necessarily productive practice of embracing together the dis and ability of dis/ability and the dis and the human of the dis/human. We acknowledge that LB's life as a disabled young person required him and his family to access support, education and services that worked with his access needs and personalised care. This is the 'dis' of life. Equally, we honour LB's abilities as a young person: human qualities that should have been has respected as much as those of a non-disabled young person. This is the 'ability' to be inherently found in any young person. His unnecessary death forces us to think again about how services, professionals and communities must acknowledge the specificities of families and young people living with the experience of disability whilst also acknowledging the common humanities of young people; to dis and to make human. It is also imperative to recognise, claim and to celebrate the dis in order to trouble the norm: '[a] dis/human position means that we recognize the norm, the pragmatic and political value of claiming the norm, but we always seek to trouble the "norm"' (Goodley \& Runswick Cole, 2014, p. 5). While disability and humanity are too often positioned as the antithesis of one another, we follow Jasbir Puar (2012, p. 50) in arguing that they are in friction, rubbing against each other in ways that are productive, desirable and have potential (Goodley \& Runswick Cole, 2014, p. 5). We and Puar are not alone, of course, in recognising the importance of the relationship between the self and the Other. This relationship lies at the heart of psychoanalytic and poststructuralist theories in which the self's construction in relation to the Other - and 


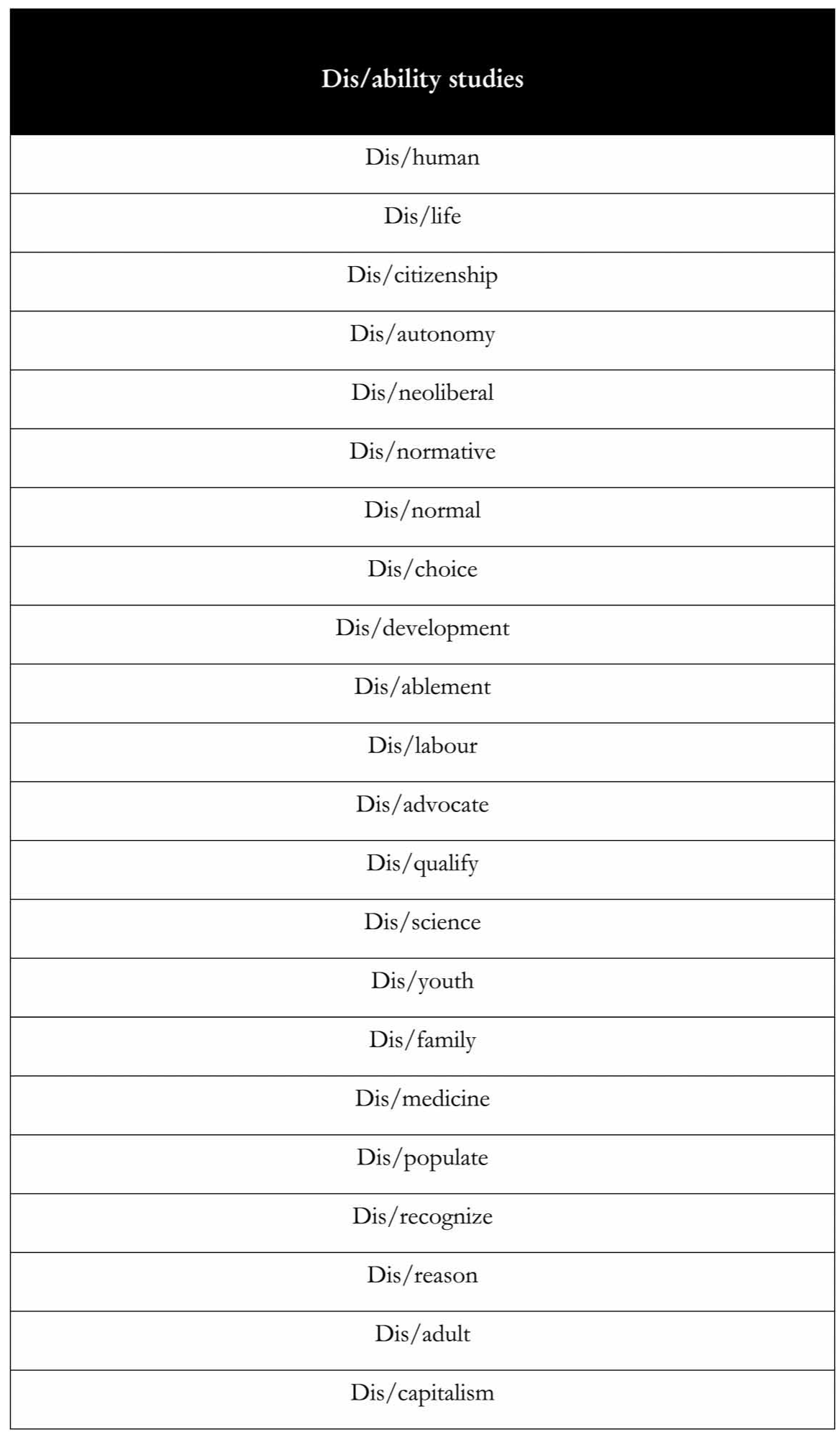

Figure 1. Dis/ability studies: becoming dis/human and other possibilities (taken from Goodley \& Runswick Cole, 2014, p. 6). 
the negation of the Other in order to claim a self - are typical everyday forms of identity formation (see Goodley, 2014, chapter 4 for an overview of some of these approaches). Our paper thus seeks to explore this frictional potential through reference to the concepts of development, family and sexuality.

Secondly, we seek to break the binarised fusion of the dis/human and move towards a more melded conception of the DisHuman. At the end of the paper, Goodley and Runswick Cole (2014, p. 13) conclude that 'we desire a time when dis/human becomes dishuman: when any thought about the human has in mind what disability does to it. It is not simply the case that we want to jettison the "/" because we find it ungainly, we want to move to a time when thinking about the human will always involve thinking about disability' (Goodley \& Runswick Cole, 2014, p. 13). In order to think about humanity through disability, we develop here the merged conception of the DisHuman, which we define as the theoretical, political and practical work done to the category of the human by the presence of disability. This is work that respects those human virtues of rights, autonomy and respect whilst also celebrating moments of mutuality, interdependence and a shared commons that expands our connections with other humans, non-humans and technology, breaking down borders and boundaries between self and other, individual and society, private and public. Our DisHuman readily occupies what Braidotti (2013, p. 13) has defined as 'the posthuman condition' - contemporary moment that urges 'us to think critically and creatively about who and what we are actually in the process of becoming'. This 'new knowing subject is a complex assemblage of human and non-human, planetary and cosmic, given and manufactured, which requires major re-adjustments in our way of thinking' (Braidotti, 2013, p. 159). In developing the DisHuman position we take further the observation that:

Disability brings something politicised and critical to posthuman theory. Our sense is that disabled people will continue to fight to be recognised as humans (in the humanist sense and register of humanism) but equally (and simultaneously) are already enacting forms of activism, art and relationality that push us all to think imaginatively and critically about a new epoch that we might term the posthuman. (Goodley, Lawthom, \& Runswick-Cole, 2014, p. 358)

The Justice for LB campaign maybe read as a demand for thinking again about how we value and treat young people - disabled and non-disabled alike - how we understand our shared humanity whilst valuing human diversity and difference. Hence, our engagement with the DisHuman is driven by our personal and professional association with the politics of disability (Goodley \& Runswick-Cole, 2010, 2011, 2012, 2014; Liddiard, $2012,2013,2014)$. Our DisHuman positionality is not, even if such a thing were possible or desirable, theory for theory's sake, rather it is an attempt to respond to the lived experiences of disabled children and families in a contemporary social and cultural global North contexts: a disabling world. Disabled children and young people are routinely subjected to the de-humanising practices of the psy-professions that render them less than fully human. Disabled children have been marginalized by or excluded from the expectations, opportunities and aspirations afforded to so-called 'typically developing children' (Goodley \& Runswick-Cole, 2010; 2011; 2012). While infants may be out of control, uncontained, unpredictable and leaky, they can escape their monstrous categorization by following, closely, a 'normal' developmental pathway that will result in them controlling and containing their unpredictable leaky bodies as they travel the path through childhood 
to (normative) adulthood (Liddiard and Slater, in press). Children who continue to be leaky, who fail to contain and control their unpredictable bodies and, who deviate from the normative trajectory, will remain monstrous, a ghostly spectre of the human (Shildrick, 1996). We argue that a DisHuman analysis in the lives of disabled children and young people can allow us to claim normativity in childhood (play, development, family, relationships) while simultaneously drawing on disability to trouble, re-shape and re-fashion narrow, neoliberal models of childhood as time of preparing citizens of the future ready to contribute to the global markets. So here we ask: what does disability do to typical, common sense normative human categories of child, youth, family and, indeed, adult? And we ask: '[w] hat do disabled children do to the widely held phenomenon of the 'normally developing child' ... )?' (Goodley \& Runswick Cole, 2014, p. 7). Is it possible to affirm family life at the same time as demanding new ways of living in and with families? Finally, we ask: in what ways can disabled young people carve out (desired) normative sexual identities and subjectivities (see Liddiard, 2012) at the same time as experience and embrace disability as a productive, pleasurable and polymorphous in the context of gender and sex/uality?

\section{The research projects}

Our engagement with the dis/human child is informed by the three recent research projects described below. More information about each of the projects can be found by visiting the links to the projects.

(1) Economic and Social Research Council (Grant No. RES-062-23-1138). Does every child matter, post Blair? The interconnections of disabled childhoods. 2008-2011 (http:// www.rihsc.mmu.ac.uk/postblairproject/).

This project was based at Manchester Metropolitan University, Manchester, UK in collaboration with the University of Newcastle-Upon-Tyne. The aim of the project was to understand what it meant to be a disabled child growing up in England. The study was based in the north of England and ran from September 2008-April 2011. The participants included disabled children aged 4-16, their parents/carers and professionals who work with disabled children, including teachers, third-sector workers, health workers and social workers. Data collection included interviews using multi-media methods. The interviews were open-ended and covered a range of issues including children and young people's experiences of health, social care, education and leisure. A period of ethnography involved attending children's birthday parties, bowling, shopping with families as well as attending impairment-specific leisure activities, including an autism specific social club, parent groups and user consultation meetings set up by local authorities, services and professionals to access the views of families. Finally, the research also included focus group interviews with professionals ranging from teachers, social workers, speech pathologists, advocates and leisure providers (http://www.esrc.ac.uk/my-esrc/grants/res-062-23-1138/ read)

(2) Economic and Social Research (Grant No. ES/K004883/1); Big Society? Disabled People with Learning Disabilities and Civil Society, Economic and Social Research Council 2013-2015. The project runs from June 2013 to June 2015 and is a partnership between four universities (Manchester Metropolitan University, the University of Sheffield, the University of Bristol and Northumbria University) working with three partner organizations (Speak Up for Action; the Foundation for People with Learning Disabilities and independent living 
consultants) in the UK. The overall research question asks: how are disabled people with learning disabilities faring in Big Society? The research is being carried out through seven overlapping and interconnected phases including interviews and ethnographic encounters. [More details available at: http://bigsocietydis.wordpress.com/]. As part of the project, we worked with young people in England who were in a transitional period as they moved from child to adult services in education, health and social care.

(3) (a) Economic and Social Science Council (Grant No. ES/F009151/1); (S)exploring Disability: Intimacies, Sexualities and Disabilities 2008-2011 (http://kirstyliddiard.wordpress.com/ sexploring-disability/). (b) Ethel Louise Armstrong Foundation and Ryerson University; (Re)Telling Sexual Stories 2012-2014 (http://kirstyliddiard.wordpress.com/retellingsexual-stories/)

(S)exploring Disability was a doctoral project (University of Warwick, UK) which explored the complex ways in which disabled people managed and negotiated their sexual and intimate lives, selves, and bodies in the context of dis/ableist cultures where they are, as Brown (1994, p. 125) states, assigned the paradoxical social categories of 'asexual, oversexed, innocents, or perverts'. Through disabled people's own sexual stories, the research traced the intricate ways in which dis/ableism contours sexual and intimate life for disabled people; what these systems of power mean in the context of disabled (hetero) sexual lives; and - most importantly of all - how these 'play out' in the material lived lives of disabled people. Its follow-up project, (Re)Telling Sexual Stories (Ryerson University, Canada), emerged as an activist-scholarship and public engagement project to communicate, translate and disseminate new knowledges from (S)exploring Disability outside of the academy to disabled people, their organisations and communities. The project was situated within the realm of public sociology; a sociology of and for the people: a form of social inquiry which values a reciprocal relationship with its public audience (Burawoy, 2005) and thus conceptualised (and theorised) the communication of knowledge as a form of social, political, economic and disability justice.

\section{The DisHuman child}

We suggest that the lives of disabled children and young people demand us to think in ways that affirm the inherent humanness in their lives but also allow us to consider their disruptive potential: this is our DisHuman child. We draw on our research projects to explore three sites where the DisHuman child emerges in moments where sameness and difference, disability and humanity are invoked simultaneously. We explore three locations: (i) DisDevelopment; (ii) DisFamily and (iii) DisSexuality.

\subsection{DisDevelopment}

In the global North, play and development are closely tied together through the practices of developmental psychology that permeate health, education and social care services (Burman, 2008). Play in childhood is 'natural', it has 'intrinsic value' - valued for its own sake - but at the same time it is deemed to have extrinsic value - as the means to an end, and that end is generally thought to be progress towards the goal of normative, productive adulthood (Goodley \& Runswick-Cole, 2010, p. 500). As we have described elsewhere, play has been systematically categorized by type and stage along a 'typical' 
trajectory (Goodley \& Runswick-Cole, 2010, p. 504). Failure to play 'properly' is a risky business as it raises a red flag for 'atypical development', difference, disorder and monstrosity. The disabled child finds him/herself in a precarious position through 'non-normative' engagement with play. $S / h e$ is the DisPlaying child. At times, it is necessary to emphasise the playing side of the binary, to assert that disabled children play too, like other children. It might seem strange for us to be arguing here that disabled children have to claim the status of the 'playing child'. But take, as an example, Jenny Lindon asking the question 'Do disabled children play?' (Lindon, 2001; p. 79 cited in Goodley \& Runswick-Cole, 2010, p. 502) in a publication about play aimed at early years practitioners in the UK. In posing the question, Lindon reveals the stark reality that not all children are automatically seen as 'playful' in early years contexts in the UK. Campaigners in the UK fight hard for equal rights to play and for accessible play spaces for disabled children and inclusive play environments. See for example John and Wheyway's (2004) guide to accessible play for disabled children. So, disabled children and their allies often find themselves in the position of having to remind others that disabled children do, indeed, play, just as 'typically developing children' do (DisPlay), but, at the same time they have to ask for accessible environments and play spaces to be included (DisPlay).

Engaging in DisPlay is no easy task and sometimes becomes the site of conflict, as Sarah (mother of a disabled child, Study 1) reveals:

The thing that didn't work was [the playworker] trying to make her do pretend play. No she is really not interested in giving a drink to the dolly, she has no interest in dollies! NO, no, this is not, NOT working!

Sarah describes an encounter between her daughter, Chloe, then aged about three, and a play worker who was trying to encourage Chloe to engage in 'age-appropriate' 'imaginative play' with tea cups and a doll - the play worker is, not surprisingly, focusing on the normative play side of the binary: DisPlay. Sarah, on the other hand, sees this as pointless, her daughter has no interest in dolls, Chloe wants to do something else ('this is NOT working'). Sarah and Chloe are making a joint appeal for DisPlay and that her different DisPlay is valued. As we have said above, play and development are seen as being inextricably related to one another in UK contexts. DisDevelopment is closely linked to DisPlay. In England, all parents of babies are given a Personal Child Health Record (Royal College of Paediatrics, 2009), known colloquially as the 'Red Book', in which they are encouraged to record their child's progress and development including weight and height, alongside developmental milestones such as crawling and walking. Children with Down's (sic) Syndrome are offered an insert for their 'Red Book' which offers additional information about the typical development of a child with Down's (sic) Syndrome. While the insert states that '[b]abies and young children with Down's syndrome have just the same needs as any child', it also offers a checklist for 'the usual developmental progress of children with the syndrome' (Down's Syndrome Medical Interest Group, 2009 , p. 2). So children with Down's (sic) Syndrome 'have just the same needs as any child' at the same time as have a different (slower) developmental pathway requiring the provision of a separate checklist for parents to track their child's progress against. We might see the addition of the insert as a focus on DisDevelopment. Yet the focus on normative, staged, typical development in the lives of children with Down's (sic) Syndrome does little to trouble concepts of norms and typical development, reinforcing 
DisDevelopment, creating another layer of 'normative', albeit 'slower', development. Sally (a mother in study 1) told us: 'I wish I had a normal child with Down's Syndrome' when her daughter Natalie's progress was 'too slow' to be mapped onto the 'normal' developmental trajectory for children with Down's (sic) Syndrome in the 'Red Book' insert. In this example, the potential for disability to trouble notions of normative development is denied as disability is merely re-inscribed back into the dominant developmental discourse. DisPlay and DisDevelopment do not always succeed in troubling the dominant norms.

\subsection{The DisFamily}

Families of disabled children have frequently been subjected to the critical gaze of academics and practitioners keen to understand the impact of having a disabled child. While traditional approaches have focused on the DisFamily, focusing on 'normative' models of family in the global North and positioning families with disabled children in relation to their failure to match up to these norms (Lazarus \& Folkman, 1984) there has been a turn to what has been described as a 'corrective' approach (Ryan \& RunswickCole, 2008) in which families of disabled children are not characterised as being either grief stricken or denial, rather the positive aspects of raising a disabled child have been highlighted (see McLaughlin, Goodley, Clavering, \& Fisher, 2008; Read, 2000; Ryan \& Runswick-Cole, 2008). This approach can be understood as an articulation of the DisFamily in which disability is celebrated for its productive potential but also normative ways of being and living in families are invoked - parenting a disabled child is just like parenting a nondisabled child ... but different (Ryan \& Runswick-Cole, 2008).

In the second project we outlined above, we worked with a family whose son was in transition from children's to adult services in the north of England. This is traditionally a stressful time for young people and their families as adult services are complex, difficult to access and often scarce and of poor quality. Anne, mother of Henry, asked for support to navigate this stage with Henry. Drawing on an established model of circles of support, ${ }^{3}$ Anne and Henry, Henry's father, Andrew and sister, Sarah, brought together a group of people to work with them towards Henry's transition to adulthood. The traditional parenting roles usually held by one or two people in families are now partly distributed: a DisFamily has emerged, not tied together by traditional kinship ties but by a commitment to meeting Henry's aspirations. The members of the circle, which meets once a month, is made up of friends of Henry as well as family members. They have worked together, meeting monthly, to smooth the transition to adult services. This DisFamily represents the productive potential of disability to bring about different ways of being and living together in 'families'.

\subsection{DisSexuality}

The sexual selves, bodies, pleasures and identities of disabled people and young people are routinely problematised, surveilled, regulated, rendered unintelligible and, in some contexts, deemed uncontrollable and in need of containment (Liddiard and Slater, in press). Paternalism, erotophobia and conservativism intersect to ensure that both groups experience 'institutional and legal restrictions on their intimate contact' (Siebers, $2008,136)$, and both are denied access to important information relating to sexual and 
intimate life (Wilkerson, 2002). For young disabled people specifically, this is rooted in a history of having seldom ever been considered, nor treated, as 'fully human' (Goodley, Lawthom \& Runswick Cole, 2014); a categorisation which, by extension, relegates one to the margins of Human sexuality. Disabled people's exclusion from this category operates on a number of levels: it compromises their entry into normative sexual and gender categories; refutes their sexual agency and selfhood; and silences their calls for sexual, reproductive and parenting rights and justice. It is not surprising, then, given that humanness, humanity and sexuality are so tightly bound in our cultures, that sexual normalcy subsists as a very powerful cultural and political category of which to gain entry (DisSexual).

Such a context requires disabled (young) people to actively claim a sexual and gendered self, body and life (Liddiard, 2012). This act of claiming sexual and intimate citizenship (Plummer, 2003; Richardson, 1996) often occurs along an emotionally laborious, troublesome and ultimately precarious trajectory whereby disabled young people must navigate and negotiate neoliberal dis/ableist heteronormative Human cultures that pathologise and constrict disabled desire; label impaired bodies and minds as undesirable and monstrous (Shildrick, 2002); and normalise and naturalise exclusory dis/ableist sexual practices and rubrics of pleasure (Liddiard, 2012, 2014) (DisSexual)

"Today we're going to learn how people with muscle weakness are going to put a condom on." I remember saying - "to be fair you're talking to someone who can't even open a chocolate wrapper, so I haven't got much hope, have I?" I remember it was almost like a shock because he [teacher] said "does that mean you're not going to use contraception?!" and I said "well no, obviously l'd just ask the other person to put the condom on ..."

The above account was taken from the sexual story of Terry, a young male heterosexual wheelchair user aged 20. Terry was in mainstream education, but was segregated for PSHE (Personal, social, health and economic) education and placed in a class with other disabled students. This was - as Terry explained - considered progressive by the school on the grounds that disabled young people needed 'special' (sic) knowledges of sex/ uality. However, Terry's encounter with his teacher reveals that, even in educational spaces where disability-specific knowledges are attempted, they often remain steeped in dis/ableism. For example, his (non-disabled) teacher's positioning of 'unsafe' sex as the only alternative to not being able to put a condom on 'independently' (read: as men should) offered Terry little creative resolution to this embodied reality of his impairment (DisSexual). Nor was it acknowledged that Terry had sufficient sexual agency (and imagination) to have already devised a dynamic solution to this intimate 'problem' (asking his sexual partner to put the condom on) (DisSexual).

To re-think this intimate 'problem' through a DisSexual lens, then, would reveal the presence of disability (previously troublesome) as a vital and transformative moment. A moment through which the (sexist) gendered politics of condom use are disrupted; a moment where dominant myths of the (masculine) sexual body as autonomous, in control and self-governing are contested; and a moment where the (Crip) sexual body emerges as a space of (embodied) relationality and interconnectedness, corporeally interwoven with other bodies and selves in multiple and creative assemblages (DisSexual). These are transformative sexual relations, especially in the context of youth.

Therefore, DisSexual ways of being can radically disrupt normative notions of sexual humanness (Liddiard and Goodley, in press), even at times where, in our research, disabled 
young people forcefully asserted a (naturalised) sexual subjectivity ('I'm a sexual being') and made claims only for normative sexual citizenship ('I want to be [sexually] normal'), locating their rights, access, agency and embodied experiences of sex/uality as central to their humanness. Feeling and enacting 'human' in such ways are undoubtedly rooted in lives and selves consistently devalued and dehumanised (Liddiard, 2014). Therefore, DisSexuality makes possible a gendered sex/uality and intimacy which keeps the DisHuman child within the (safer) boundaries of sexual normalcy. Crucially, at the same time, DisSexuality draws on disability to invoke (emancipatory) posthuman modes of sex/uality which value (and celebrate) inter/dependence; queer; radical relationality, collaboration and collectivity in ways that can be emancipatory for all sexual subjects.

\section{Conclusion}

In this paper, we have attempted to sketch out - through the narratives of and around disabled young people - three DisHuman positions that capture the appeals made to traditionalist notions of the humanist human (being respected and recognised, valuing autonomy and competence, acknowledging the essential qualities of being a person) alongside the disruptive potential of disability to reconfigure different ways of being, becoming and enacting our humanities. Rosi Braidotti (2013) has suggested that the twenty-first century subject is a complex blend of human and technology - a moulding together of wetware (brains and bodies) and hardware (technology and social media) that demands how we might rethink what it means to be a human being. Our sense is that the presence of disability - whether it be associated with physical, sensory or cognitive differences and impairments (and those many occasions when impairment remains undiagnosed or misunderstood) - brings something even more technological to the table of human diversity. Indeed, were we to take a Foucauldian notion of technologies of the self then we might suggest that disability is a world-leader in the high-tech branding of human difference. The epidemic of signification around disability and impairment evident for example in the re-description of labels, diagnoses and conditions outlined in the 2013 DSM-V - suggests that disability is becoming one of the major signifiers of human diversity in the twenty-first century. Questions and concerns abound in relation to who actually is funding and driving forward these categorisations of human difference and the more pathological notions of 'disorder' and 'distress'. China Mills' recent (2014) book on the decolonisation of mental distress reminds us that too often the 'dis' of disability and the deficits of impairment are the product of globalising discourses of psychiatrisation and psychologisation bank-rolled by Big Pharma and cast across the world's population through the practices of the psy-disciplines. We need to be careful, then, about how we conceptualise the 'dis' of our DisHuman position. Our belief that the human is touched, disrupted, shaken up and reframed by disability comes from a sense that disability is a relational concept; tied to a host of institutional and disciplinary practices, phenomenologically experienced subjectively, materially, culturally and discursively. Each and every disabled young person brings with them a personally embodied account of disability; incorporating aspects that we might feel initially able to objectively measure (e.g. a child cannot use their eyes) that rapidly becoming codified, reacted to, socially and culturally made sense of in complex, specific and temporal ways (e.g. to not see becomes known in a culture that is largely one assumed to be seeing). When we think of the 
DisHuman condition, we want to retain this complex emerging conception of disability: that transcends boundaries of impairment/disability; personal/public and self/other. Crucially, we consider disability to broaden what it means to be human; to respect but also go beyond notions of autonomy, competence and choice and to think again about the extended qualities associated with what it means to be human. Finally, and perhaps simply, our framing of disabled childhoods in terms of the DisHuman condition makes a case for thinking about childhood, culture and society in ways that contest the rigidity of what counts as human. We know that when LB died, his humanity was not taken seriously. We also know from the stories about LB and from the ensuing JusticeforLB campaign that his family and their allies are unprepared to accept that human diversity and disability should always be packaged as somehow not human. The JusticeforLB campaign, like the accounts of the young people and families we present in this paper, remind us of what might be achieved when we respond collectively to think again about what we value as (post)human beings.

\section{Acknowledgements}

We would like to acknowledge and thank the Economic and Social Research Council for supporting and funding the three research projects upon which this paper draws RES-062-23-1138; ES/K004883/ 1; ES/F009151/1.

\section{Disclosure statement}

No potential conflict of interest was reported by the authors.

\section{Notes}

1. http://mylifemychoice.org.uk/champions/justice/ see also on twitter @JusticeforLB.

2. Here we acknowledge as an example the case of the death of Nico Reed http://justicefornico.org/

3. See: http://www.circlesnetwork.org.uk/index.asp?slevel=0z114z115\&parent_id=115

\section{References}

Anon. (2009). The monster inside my son. http://www.donotlink.com/framed?513327

Braidotti, R. (2013). The Posthuman. London: Polity.

Brown, H. (1994). An ordinary sexual life? A review of the normalisation principle as it applies to the sexual options of people with learning disabilities. Disability and Society, 9(2), 123-144.

Burawoy, M. (2005). For public sociology. American Sociological Review, 70(1), 4-28.

Burman, E. (2008). Developments: Child, image, nation. London: Routledge.

Curran, T., \& Runswick-Cole, K. (2014). Disabled children's childhood studies: a distinct approach? Disability \& Society, 29(10), 1617-1630.

Down's Syndrome Medical Interest Group. (2009). PCHR insert for children with down's syndrome. Retrieved from http://www.healthforallchildren.com/wp-downloads/PCHR-Insert-Downs.pdf

Evans, S. (2004). Forgotten crimes: The holocaust and people with disabilities. Chicago: Ivan R Dee.

Goodley, D. (2014). Dis/ability studies. Theorising disablism and ableism. London: Routledge.

Goodley, D., Lawthom, R., \& Runswick-Cole, K. (2014). Posthuman disability studies. Subjectivity, 7(4), 342-361. doi:10.1057/sub.2014.15.

Goodley, D., \& Runswick-Cole, K. (2010). Emancipating play: Dis/abled children, development and deconstruction. Disability \& Society, 25(4), 499-512. 
Goodley, D., \& Runswick-Cole, K. (2011). The violence of disablism. Journal of Sociology of Health and Illness, 33(4), 602-617.

Goodley, D., \& Runswick-Cole, K. (2012). The body as disability and possability: Theorising the 'leaking, lacking and excessive' bodies of disabled children. Scandinavian Journal of Disability Research, 15(1), 1-19.

Goodley, D., \& Runswick Cole, K. (2014). Becoming dishuman: Thinking about the human through dis/ ability. Discourse: Cultural politics of education. Advance online publication. doi:1080/01596306. 2014.930021.

Haraldsdóttir, F. (2013). Simply children. In: T. Curran \& K. Runswick-Cole (Eds.), Disabled children's childhood studies: critical approaches in a global context (pp. 13-21). Basingstoke: Palgrave Macmillan.

Hevey, D. (1992). The creatures time forgot: Photography and disability imagery. London: Routledge. HMSO. (2010). The equalities act. London: HMSO.

John, A., \& Wheyway, R. (2004). Can play, will play: Disabled children and access to outdoor playgrounds. London: National Playing Fields Association (NPFA).

Kittay, E. F. (2011). The ethics of care, dependence and disability. An International Journal of Jurisprudence and Philosophy of the Law, 24(1), 49-58.

Kittay, E. F., \& Carlson, L. (2010). Introduction: Rethinking philosophical presumptions in the light of cognitive disability. In E. F. Kittay \& L. Carlson (Eds.), Cognitive disability and its challenge to moral philosophy (pp. 1-26). Chichester, West Sussex: Wiley-Blackwell.

Lazarus, R. S., \& Folkman, S. (1984). Stress, appraisal and coping. New York: Springer.

Lee, S. (2010, September). My son is not a monster: He's autistic. The Daily Mail. Retrieved from http:// www.dailymail.co.uk/health/article-1313232/My-child-monster-He-autistic.html

Liddiard, K. (2012). (S)exploring disability: Intimacies, sexualities and disabilities (Unpublished PhD Thesis), University of Warwick.

Liddiard, K. (2013). Reflections on the process of researching disabled people's sexual lives. Social Research Online, 18(3), 10.

Liddiard, K. (2014). The work of disabled identities in intimate relationships. Disability and Society, 29(1), 115-128. doi:10.1080/09687599.2013.776486.

Liddiard, K., \& Goodley, D. (in press). Disability and impairment. In B. Turner et al. (Eds.), Encyclopedia of social theory. London: Wiley.

Liddiard, K., \& Slater, J. (in press). "Like, pissing yourself is not a particularly attractive quality, let's be honest": Learning to contain through youth, adulthood, disability and sexuality. Sexualities, (Special issue: Pleasure and desire).

Lindon, J. (2001). Understanding children's play. Cheltenham: Nelson Thorns.

McLaughlin, J., Goodley, D., Clavering, E., \& Fisher, P. (2008). Families raising disabled children: Enabling care. Basingstoke: Palgrave MacMillan.

Mills, C. (2014). Decolonizing global mental health: The psychiatrization of the majority world, London: Routledge.

de Montaigne, Michel. "Of a monstrous child." Trans. Charles Cotton. 1580. Quotidiana. Ed. Patrick Madden. 22 September 2006. 12 October 2014 <http://essays.quotidiana.org/montaigne/monstrous_child/>.

Plummer, K. (2003). Intimate citizenship: Private decision and public dialogues. Seattle and London: University of Washington Press.

Puar, J. (2012). 'I would rather be a cyborg than a goddess': Becoming-intersectional of assemblage theory. Philosophia: A Journal of Feminist Philosophy, 2(1), 49-66.

Read, J. (2000). Disability, family \& society: Listening to mothers. Buckingham: Open University Press. Richardson, D. (1996) Theorising sexuality. Buckingham: Open University.

Rieser, R. (2006). Disability equality: Confronting the oppression of the past' in 'education, equality and human rights. In M. Cole (Ed.), Education, equality and human rights (Chapter 7 pp. 159-189). London: Routledge.

Royal College of Paediatircs. (2009). Personal child health record. Retrieved from http://www.rcpch.ac. uk/child-health/public-health/personal-child-health-record/personal-child-health-record

Ryan, S., \& Runswick-Cole, K. (2008) Repositioning mothers: Mothers, disabled children and disability studies. Disability and Society, 23(3), 199-210. 
Shildrick, M. (1996). Posthumanism and the monstrous body. Body \& Society, 2(1), 1-15.

Shildrick, M. (2002). Embodying the monster: Encounters with the vulnerable self. London: Sage.

Siebers, T. (2008). Disability theory. London: University of Michigan Press.

Skitteral, J. (2013). Transitions? An invitation to think outside Y/our problem box, get fire in your belly and put pebbles in the pond. In: T. Curran \& K. Runswick-Cole (Eds.), Disabled children's childhood studies: Critical approaches in a global context (pp. 22-29). Basingstoke: Palgrave Macmillan.

Taylor, A. (2013). "Lives worth living": Theorizing moral status and expressions of human life. Disability Studies Quarterly, 33 (4). Retrieved from http://dsq-sds.org/article/view/3875

United Nations. (2007). The convention on the rights of persons with disabilities. Retrieved from http:// www.un.org/disabilities/default.asp?id=150 [02.12.13].

Wilkerson, A. (2002). Disability, sex radicalism and political agency. NSWA Journal, 14(3), 33-57. 